\title{
IoT Piggy Bank for Money Saving Habit Instillation
}

\author{
${ }^{1}$ Eng Yee Wei and ${ }^{2}$ Wee Bui Lin \\ ${ }^{1,2}$ Faculty of Computer Science and Information Technology, Universiti Malaysia Sarawak, 94300 Kota \\ Samarahan, Sarawak, Malaysia, Malaysia \\ email: ${ }^{19083 w e i @ g m a i l . c o m, ~}{ }^{2}$ blwee@unimas.my
}

Date received: 18 December 2020

Date accepted: 24 September 2021

Date published: 18 October 2021

\begin{abstract}
Children nowadays are overwhelming with luxurious things and have only little or even no money concepts where most of the kids just reach out to their parents for buying anything they want. This could be an issue for parents, hence kids should be taught the value of money and knowing that save their own money is important to purchase anything they desired. This project proposed an innovative way to inculcate saving behaviours in children using an IoT Piggy Bank. This goal-directed approach allows children to set their saving goals (values of their desired items) and form a saving habit slowly through their saving routines toward their saving goals. Every saving made by the children will be tracked in a mobile app and a buzzer will be triggered as a reinforcer to alert children when they do not save regularly. The user acceptance testing (UAT) of the proposed prototype has shown the majority of the parents (90\%) agreed that the proposed IoT piggy bank is very suitable for children to instil saving habit. Most of the children have reacted positively where they were having lots of fun when trying on the IoT piggy bank and expressed that they would continue to use it for saving in the future.
\end{abstract}

Keywords: IoT, piggy bank, saving behaviour, goal tracking, money management, goal-directed behaviour, prototyping.

\section{Introduction}

According to Cambridge Counselling Corporation ("Teaching Kids the Value of Money," n.d.), kids nowadays have only little or even no money concept where most of the kids just reach out to their parents for buying anything they want. A study by Lewis and Scott (2000) has shown that the level of economic awareness and knowledge among older children are relatively limited. The never-ending demand from kids could be an issue for parents and shows a sign of inadequate economic awareness in kids. Therefore, kids should be taught about the value of money and economic knowledge through their daily economic transactions in their early childhood.

Saving is not easy for many people. According to Kamawar et al. (2019), saving is a skill that requires future expectation and self-control to do so. There is a direct relationship of self-control influence on saving behaviour as conveyed in Ghufron and Risnawitaq (2017) and Sirine and Utami (2016). Additionally, parents' influences also play important role in instilling saving behaviour in early childhood. Firmansyah (2013) stated that the parents' saving behaviours and support in saving promote children to save for their future. Another study by Chalimah et al. (2019) has also proven that the role of parents, financial literacy, and self-control and future perceptions has effects on saving behaviour of students. Save money for something their really want could be one of the determinants of children's savings behaviours. The goal-directed approach with a proper application of reinforcements could stimulate the formation of saving habits in children more effectively.

There are some solutions on IoT piggy bank development that have been designed to serve different purposes from coins detection to saving behaviour tracking. However, there still lacks solutions for children to learn the value of money and to acquire saving skills in order to save up for the things they wish to own. This project proposed an innovative way to inculcate saving behaviours in children using an IoT Piggy Bank that allows children to set their saving goals based on the values of their desired items and form a saving habit slowly through their saving routines toward the saving goals. For every saving they made, the money will be tracked in a mobile app and a buzzer is used as a reinforcer to alert children when they do not save regularly. With this goal-directed approach, saving coins in piggy banks becomes more interesting compared with the traditional piggy banks. 


\section{Literature Review}

Various works applying IoT technology on piggy bank have been done to serve similar purposes of this project. The following sections discuss the reviews of three existing IoT Piggy Banks, namely Smart Piggy Bank, Coink and Pennie.

\subsection{Review on Related Works}

\subsubsection{Smart Piggy Bank: In-home Banking System for Children}

Smart Piggy Bank is an IoT Piggy Bank that connects to an online bank account (Lee et al., 2017). The purpose of this piggy bank is to detect the saving behaviour of children. This IoT Piggy Bank is connected through a smartphone application via Bluetooth transmission. With this application, it can help parents to track their children's saving behavioural pattern. The IoT product is focusing on the saving behaviour of children rather than the amount of money that has been saved in real-time. Parents can see the children's saving trend through the mobile application. The smart piggy bank does not consist of correct coin value detection where their emphasis is only on motivating children to save money.

\subsubsection{Coink - An IoT Piggy Bank}

Cojo company has developed a type of IoT Piggy Bank named Coink (León Peque \& Casas, 2018). It is an IoT Piggy Bank that used to detect coin by using a magnetic sensor that built inside the piggy bank. It is a simple piggy bank that is able to differentiate between $1 €$ and $2 €$ coins. Coink uses 3D Magnetic Sensor $2 \mathrm{GO}$ to detect the magnetic field produced by a passing coin inserted through the ramp built inside the piggy bank. Before any coins are inserted, there is one webpage showing on the computer screen. The data of the total amount of money saved is transferred to the cloud service. Progress tracking of this piggy bank is displayed in a browser that can instantly show out the coin picture and its value. Coink is able to keep track of user's saving in a graph format.

\subsubsection{Pennie: An Arduino-Powered IoT Piggy Bank}

Pennie is an Arduino powered IoT Piggy Bank which is designed by a first-year university student named Yuko Kanai. It is an IoT Piggy Bank used to track the progress of a physical half marathon training at the meantime depositing money in a digital form for saving purposes and also self-rewarding for each achievement ("PENNIE: An Arduino Powered IoT Piggy Bank," 2020). The user of Pennie has to wear a bracelet which connected to the piggy bank Pennie when running for a half-marathon. When there are certain steps the user has acquired, the training lamp will light up on the piggy bank and a fixed amount of money in digital format will be accumulated by then. This project is aiming to cultivate a saving behaviour for kids while Pennie piggy bank uses piggy bank as a guide to motivate user on half-marathon training.

\subsubsection{Downside and Improvement on related works}

Based on the findings from the review above, Smart Piggy Bank, Coink and Pennie are having saving track features. However, they do not have a proper way to keep track of the saving done or to see the trend of saving. Therefore, this project proposed to add on the functions of goal-setting and saving tracking visualization on the mobile application to overcome the above-mentioned problems. Besides, there is also a reminder function built on the piggy bank to remind children to do their savings regularly.

\subsection{Review on Type of Detector/Sensors}

In terms of detection devices reviews, there are different types of coin detectors or sensors used by each of the IoT Piggy Bank. Smart Piggy Bank uses a needle switch sensor, a type of coin pusher that is normally fixed in arcade game accessories. It detects coins only when a coin is dropped and pushed over the sensor as it works mechanically as shown in Figure 1 below.

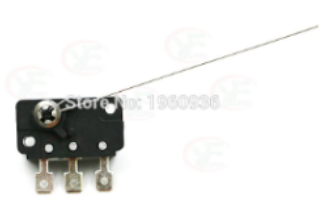

Figure 1: 3-feet micro switch needle-type microswitch for old mechanical coin select acceptor arcade game accessories 
Secondly, Coink used a magnetic sensor to detect coins and to differentiate the various type of coins by analysing each coin's magnetic field and present it in a graph. The example of a magnetic sensor is shown in Figure 2 below.

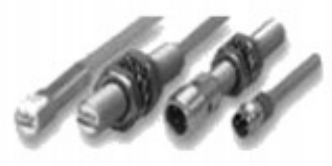

Figure 2: Example of a magnetic sensor

\section{Methodology}

This project adopts the improved Waterfall SDLC methodology (Royce, 1970) to develop the system prototype. Figure 3 depicts the 5 phases and the process activities involved in each phase of this project development. The details of the phases will be discussed in the following sections.

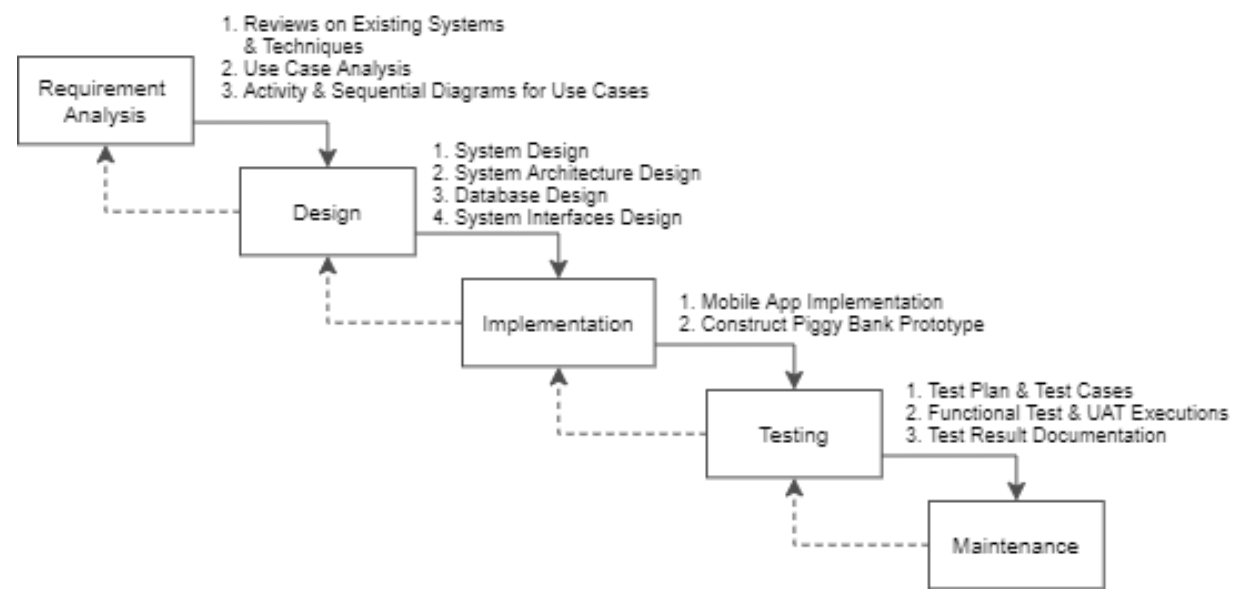

Figure 3: The waterfall model for IoT Piggy Bank for Saving Behaviour Instillation project

\subsection{Requirement Analysis and Definition}

The requirement analysis is the first phase of the Waterfall SDLC. Firstly, the problem statements are identified and analysed. All the requirements are gathered and documented. Use case diagram is used to describe the system's requirements and the scope of the system as depicted in Figure 4. It identifies the interactions between the system and actors. There are 4 actors which are children, parent, sensor and buzzer. Children can only save money in the piggy bank after discussion with their parents, parent help children to set saving goal. Parent can also view children's saving trends. Then, the sensor detects the inserted coins and the buzzer triggers the alarm when no saving activity is detected for a certain period.

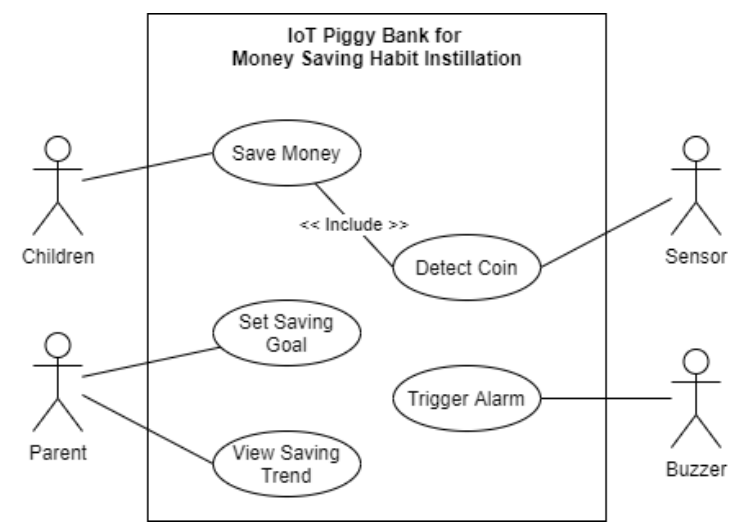

Figure 4: Use case diagram of IoT Piggy Bank for money saving habit instillation 


\subsection{System Design}

There are 4 types of designs involved in IoT Piggy Bank prototype development, namely module design, system architecture design, database design, user interfaces design.

\subsubsection{Module Design}

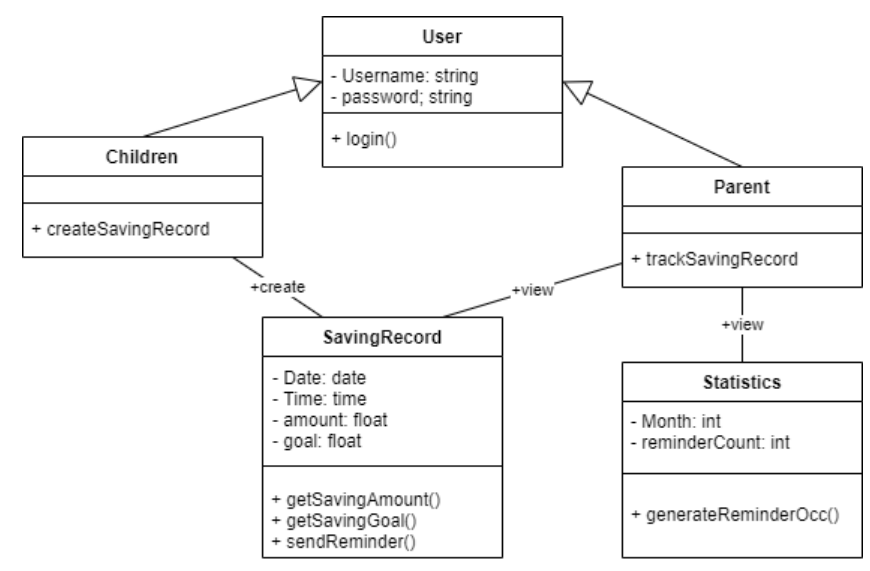

Figure 5: Class Diagram for the system design of the proposed IoT Piggy Bank

UML class diagram is used to describe the structure of the proposed prototype as shown in Figure 5 above. There are 3 main classes which are user, saving record and statistics, whereas the children class and parents class are derived from the user class. Besides, parent can view the statistics of savings trends and daily saving records created by the children.

\subsubsection{System Architecture Design}

Figure 6 below illustrates the system architecture design of the IoT Piggy Bank that consists of Arduino Uno which is connected with Cytron ESP8266 WiFi shield as a controller and communication module to become an integrated central component. This integrated central component will be used to connect all the requirement IoT devices which are IR sensor, Buzzer, servo motor and LCD screen. Besides that, the IoT device is also connected to an online database and mobile app to allows parents to monitor their children's saving behaviour.

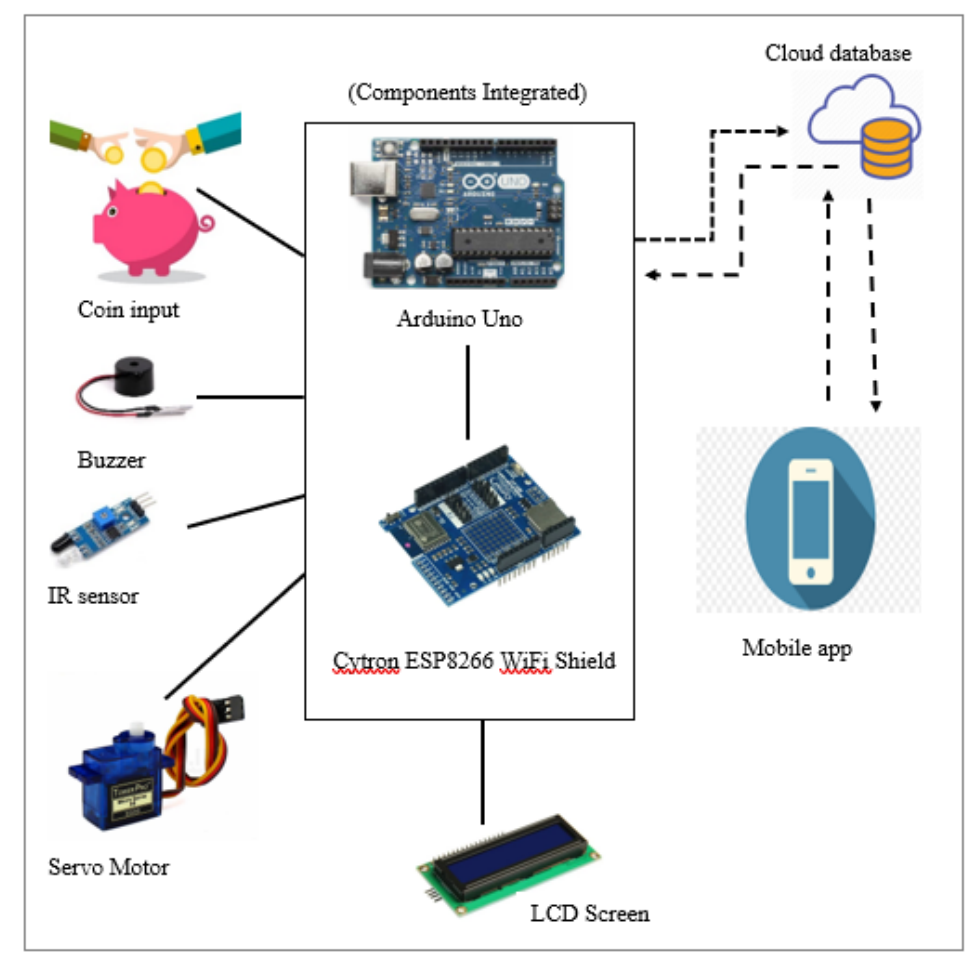

Figure 6: System Architecture Design of the proposed IoT Piggy Bank 
When the user inserts a coin into the piggy bank, the servo motor will serve as a coin gate at the coin entrance and the IR sensor connected to the Arduino Uno will detect the incoming coin and recognize its value. The value detected is calculated and send to the cloud database. Then, the value inserted will be retrieved from the cloud database to be displayed on the LCD screen after one complete round of money insertion. On the other hand, user can access the mobile app to track the saving trend over a period of time. The information stores inside the mobile app is also retrieved from the cloud database. When user resets the total amount of money in the mobile app after a goal has been achieved, then the LCD display attached to the Arduino will also be reset to the default value. The mobile app and the online database perform two-way communications with the Arduino. Lastly, when the Arduino tracks that the user did not save money for a period of time, the buzzer will sound and notify the user.

\subsubsection{Database Design}

Another class diagram is used to model the logical design of the database for the proposed IoT Piggy Bank. Figure 7 shows the entities of the database and the relationships between each entity, where the user can set saving goals, saves money, and get reminder alerts.

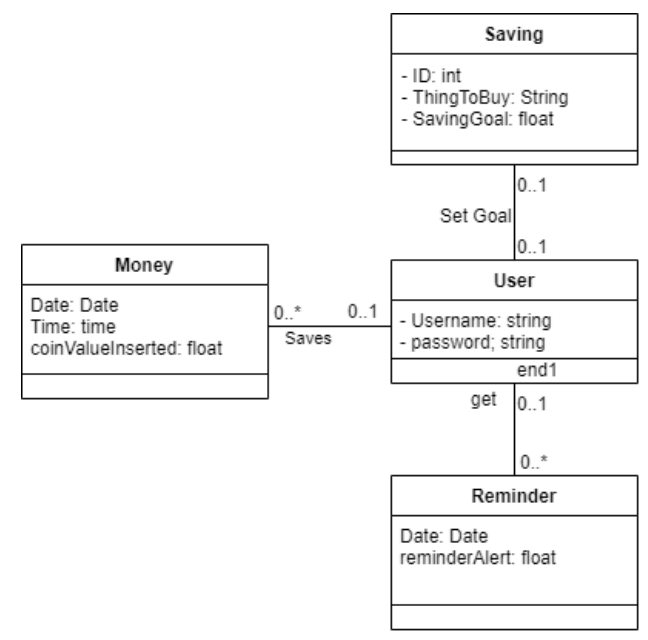

Figure 7: Databased Design of the proposed IoT Piggy Bank

\subsubsection{Software User Interface and Prototype Design}

\subsubsection{IoT Piggy Bank Mobile App User Interface Design}

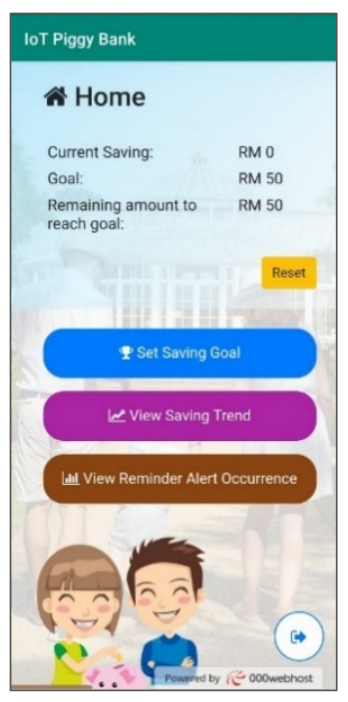

(a)

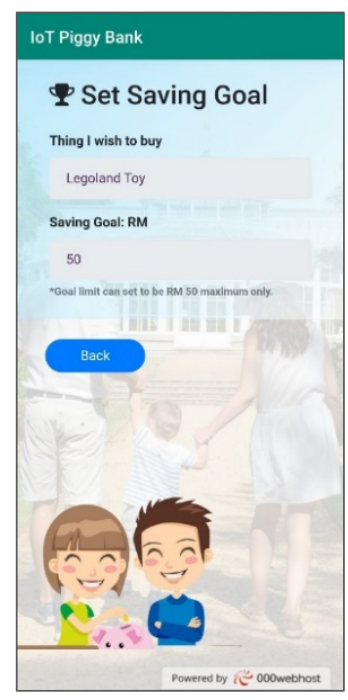

(b)

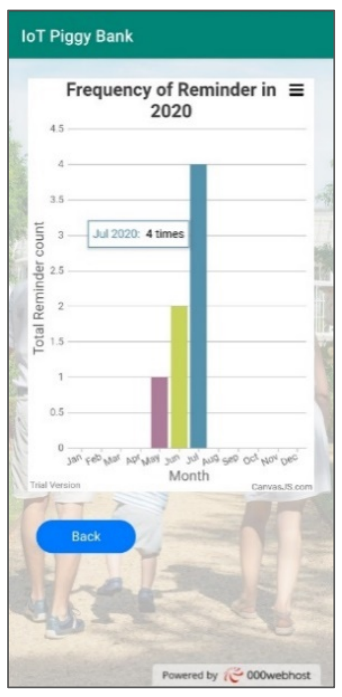

(c)

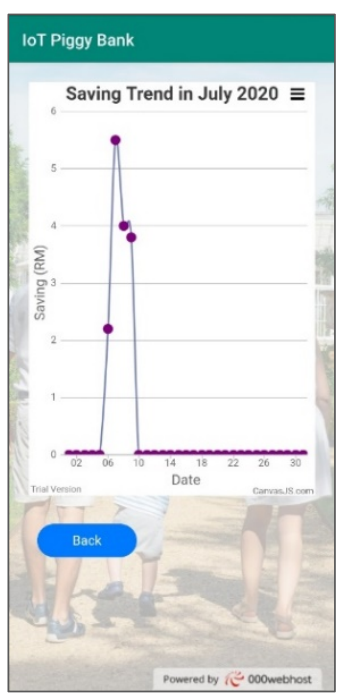

(d)

Figure 8: User Interfaces for IoT Piggy Bank mobile app: (a) Main interface (b) Saving goal setting (c) Kid's monthly saving trend and (d) Frequency of reminder 
Figure 8 shows some user interfaces of the mobile app for the proposed IoT Piggy Bank. The parents are allowed to choose from the options provided on the main page (a) and they can set a saving goal for their kids as in (b). Besides that, parents can monitor the saving behaviour of their children by viewing the saving trend (c) and the reminder alert occurrence (d) to know how often their children have not been saving any money.

\subsubsection{IoT Piggy Bank Prototype Design}

The hardware setup design of the prototype is shown in Figure 9 below where a breadboard is used as a base to connect with all the hardware components.

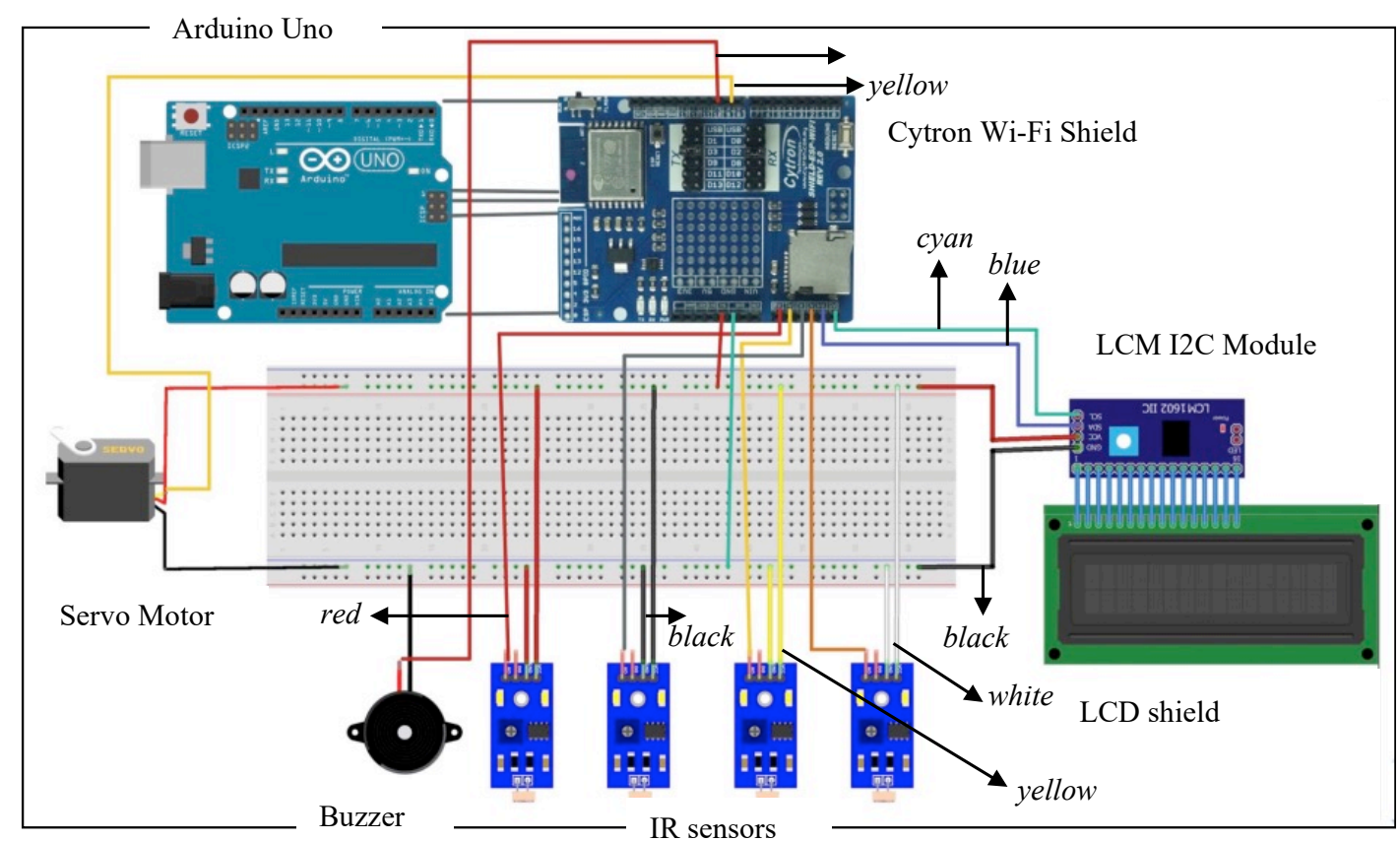

Figure 9: The hardware setup design for the IoT Piggy Bank prototype

\section{System Implementation}

Implementation of the IoT Piggy Bank includes hardware and software implementation. Figure 10 shows the outer design of the IoT Piggy Bank prototype. The blue data cable is used to connect to a power bank or computer USB port. Coin should be inserted into the coin hole and wait for the inner coin gate to open again before the next coin is inserted. There is also a light indicator that indicates a coin is detected at the coin gate and has been inserted in the collector correctly. The value of inserted coins is displayed on the LCD screen.

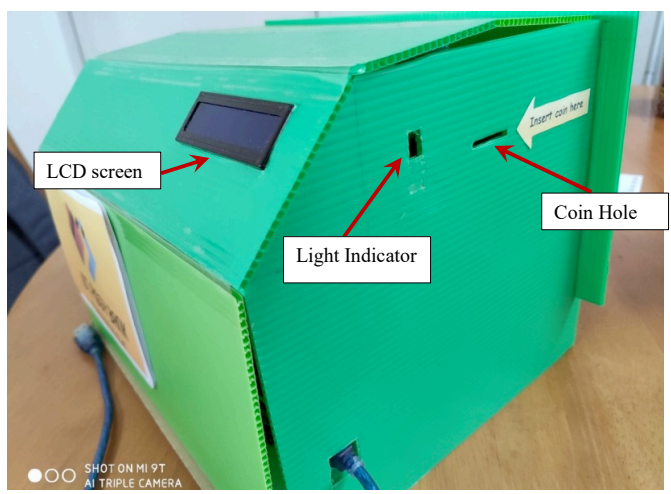

Figure 10: Outer look of the IoT Piggy Bank prototype

Figure 11 shows the internal structure of the IoT Piggy Bank prototype. When user inserts a coin into the coin gate, the servo motor will open, and the coin can slide in the coin slope to the respective coin collectors based on the coin value detected. The coin is detected once it passes through the coin slot and is sensed by the IR sensors. The buzzer will sound if user did not save money continuously for a period of three days onwards. 


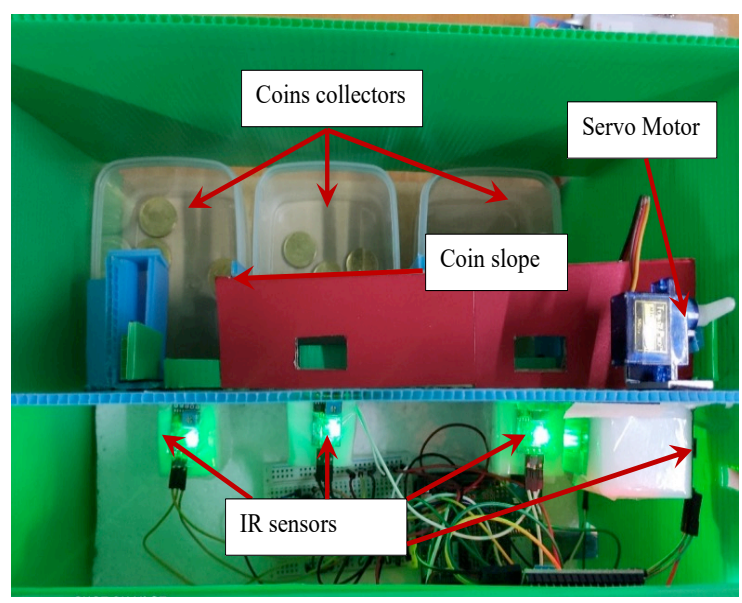

Figure 11: The inner design (Top View) of the IoT Piggy Bank prototype

It is worth discussing that the implementation phase is one of the most important phases and some difficulties have been encountered. To connect every wire in a correct position is considered a moderate difficulty task however the most challenging problem occurs during the electronic components building process. For example, the IR sensors should have their positions correctly set to capture the falling moment of a coming coin, some coins might have skipped from the sensing process and are not being tracked due to their falling pose. Besides, the prototype sliding slope may obstruct the movement of a coming coin due to the surface of the material made and this would take few times of coins sliding in order to reduce the friction and a later smooth flow. To overcome this problem, grease is first to be tried by applying it on the sliding slope however this has caused the coin is sliding down too fast and missed off the coin slots. The sliding slope material is also affected by the humidity where the coins will not be able to slide smoothly.

\section{$5 \quad$ Testing and Result Analysis}

Two types of testing have been performed on the proposed prototype, functional testing and User Acceptance Testing (UAT). For functional testing, there is a total of 11 test cases have been carried out across 6 use cases. Out of 11 test cases, 10 had passed and only one failed. The coin detection test case failed due to the coin falling position was escaped away from the IR sensor detection and caused an inaccurate result as discussed in the previous section. This problem had been observed and improved by adding a valve on each coin slot to avoid the falling coins away from sensor detection, hence increased the accuracy rate of coin detection from $50 \%$ to $90 \%$.

On the other hand, an UAT has also been carried out by 15 potential users, where 10 parents ( 5 couples) and 5 children of these pair of parents in the age range of 6 to 8 took part in this testing. These users are required to test on both the piggy bank prototype and the mobile app according to the instructions given and the answer to the survey questions after completed the testing.

The survey is diversified into 3 perspectives which are product suitability, product functionality and product satisfaction. Result analysis shows that there are more than $90 \%$ of parents believe (60\% agreed and 30\% strongly agreed) that the IoT Piggy Bank is suitable for their child to instil saving habits as shown in Figure 12.

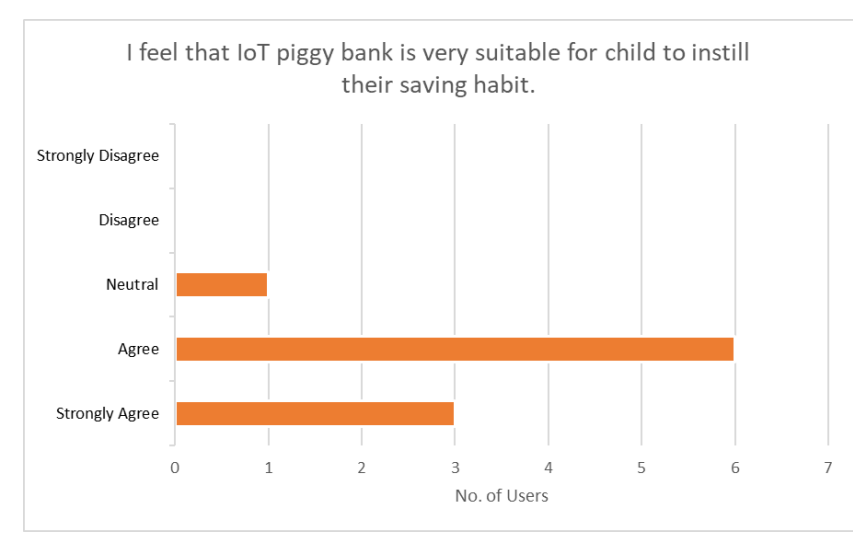

Figure 12: Graph of Product Suitability Perspective Survey Result (Parents) 
From the children perspective, $80 \%$ of the testers expressed that they had a lot of fun trying on the IoT Piggy Bank as shown in Figure 12. This implies that children are showing a positive reaction to it and drive them to continue using it for saving in the future.

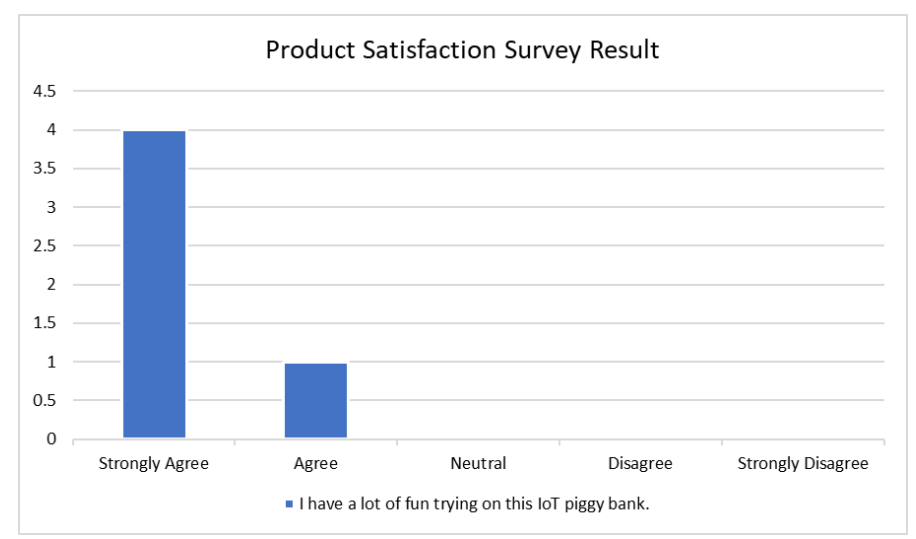

Figure 11: Graph of Product Satisfaction Survey Result (Children)

From the product functionality survey analysis, most of the users were able to operate the piggy bank based on the instructions given. This has proven that the prototype and mobile application are user-friendly, both the piggy bank prototype and mobile application are synchronized smoothly and correctly. Moreover, the alarm can remind users when children do not perform saving in 3 days consecutively. In the case of power outage either accidentally or intentionally, the alarm function and saving goal will be resumed after power is back on. Therefore, every plus point above mentioned is showing the IoT piggy bank is helpful for children to instil their saving behaviours.

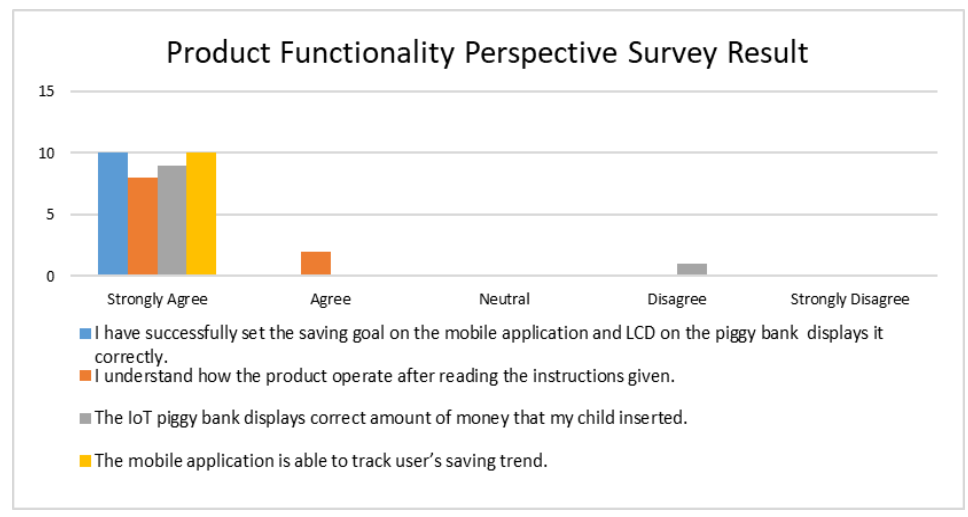

Figure 14: Graph of Product Functionality Perspective Survey Result

The overall results of the survey in 3 perspectives, product suitability, product functionality and product satisfaction are summarized in Table 1 below:

Table 1: Survey Result Interpretation

\begin{tabular}{|l|l|l|l|}
\hline & Product Suitability & Product Satisfaction & Product Functionality \\
\hline What did I find? & $\begin{array}{l}\text { Most of the parents agree } \\
\text { that the IoT piggy bank is } \\
\text { suitable for cultivating their } \\
\text { children's saving } \\
\text { behaviour. }\end{array}$ & $\begin{array}{l}\text { Most of the children are } \\
\text { greatly satisfied with the } \\
\text { IoT piggy bank and showing } \\
\text { positive feedbacks. }\end{array}$ & $\begin{array}{l}\text { Most of the users have a } \\
\text { good user experience on } \\
\text { using the new developed } \\
\text { IoT Piggy Bank } \\
\text { prototype. }\end{array}$ \\
\hline $\begin{array}{l}\text { What did I not } \\
\text { find? }\end{array}$ & $\begin{array}{l}\text { The survey did not include } \\
\text { which perspective of the } \\
\text { suitability attracted parents. }\end{array}$ & $\begin{array}{l}\text { The survey did not include } \\
\text { that which part of the } \\
\text { product that makes children } \\
\text { most satisfy while using it. }\end{array}$ & $\begin{array}{l}\text { The survey did not } \\
\text { investigate on which } \\
\text { function does user like } \\
\text { the most. }\end{array}$ \\
\hline
\end{tabular}




\begin{tabular}{|l|l|l|l|}
\hline $\begin{array}{l}\text { What did I find that } \\
\text { I was not expecting } \\
\text { to find? }\end{array}$ & $\begin{array}{l}\text { The survey portrayed an } \\
\text { unexpected high } \\
\text { acceptance rate of parents } \\
\text { regarding this product. }\end{array}$ & $\begin{array}{l}\text { The survey conveys a } \\
\text { message that children are } \\
\text { adapting themselves to } \\
\text { technology. }\end{array}$ & $\begin{array}{l}\text { The IoT Piggy Bank is } \\
\text { very user friendly where } \\
\text { every user knows how it } \\
\text { works according to } \\
\text { instructions given. }\end{array}$ \\
\hline
\end{tabular}

\section{Contributions, Limitations and Future Works}

Apart from tracking the saving behaviours of the children, this project is focusing on developing an IoT piggy bank to help children save money and form saving habits more systematically. The main contributions of this project are the children can learn the value of money from the items they wish to buy while at the same time they also learn how to justify, negotiate, and make agreements during their discussion with parents before setting their saving goals and practice to save money regularly until their goals are achieved. Throughout the process, children might be get distracted by other factors, for instance desiring for other new items, being forgetful and etc., therefore children also learn to have self-control and stay persistent towards achieving their goals as the eventually formed the saving habit. The amount tracking displayed on LCD screen and mobile app provide visuals that illustrate their saving goals and how their money is growing would encourage them to keep going. Meanwhile, parents also played important role in teaching children the value of money through their daily economic transactions and inculcate children the importance of saving money by encouraging children to save money for the things they want to buy.

One of the limitations of this IoT prototype is the user unable to insert coins into the coin hole continuously, where the coin gate will close after a coin is inserted and user must wait for a while until the coin gate is opened again for user to enter the next coins. This is to ensure the sensor able to detect the falling coin perfectly and track the inserted coins values accurately. Another limitation of this product is it cannot be operated if there is internet interruption, or the network is down unexpected. The internet connection will affect the data tracking of money saving when there is a connection loss. To avoid the problem, the internet connection stability should be checked and configured frequently. Besides, a negative reinforcer (buzzing alarm) is used to remind children to save regularly might temporarily work for a short-term period. Children will become indifferent to the alarm over time and unmotivated to continue saving in a long run.

For future works, this IoT piggy bank prototype can be enhanced by modifying it into a more humanized mechanism, for instance, to include an indicator to notify the user before the coin gate closes to overcome the problem of late coin insertion timing that clashes just before the coin gate closed or allow user to insert coins continuously without falling into timing restriction and always perfect coin detection. Furthermore, the other future work is to add the ability to store offline data such as coin insertion during network down. Then, despite the internet connection being down, children still able to save money into the piggy bank and the data will be updated back to the server once the internet connection is resumed. Lastly, positive reinforcers could be added to the piggy bank itself to raise children's interest in a more effective way such as playing their favourite song or movie for them through the app whenever they have achieved certain portions of their saving goals. This will make them feel more rewarded and motivated to keep on saving in a much more interesting way.

\section{Conclusions}

In conclusion, the IoT piggy bank prototype and a mobile application have been developed successfully. Children are able to set their saving goals and save up regular for the items they wish to have. Children are frequently reminded with a buzzer when they have not saved money for consecutive 3 days. Both saving trends and the frequency of reminder alerts can be viewed by parents to monitor the saving behaviour of their children. The feedbacks have shown that children were having a lot of fun while they are practising the habit of saving money and parents believe that the proposed IoT Piggy Bank helps inculcate the habit of saving in their children.

\section{Acknowledgements}

The authors are grateful to all the faculty members of the Faculty of Computer Science and Information Technology, Universiti Malaysia Sarawak and friends who participated in the interviews and usability testing, without their support the study could not have been conducted. 


\section{References}

Chalimah, S. N., Martono, S., \& Khafid, M. (2019). The Saving Behavior of Public Vocational High School Students of Business and Management Program in Semarang. Journal of Economic Education, 8(1), 22-29. Retrieved from http://journal.unnes.ac.id/sju/index.php/jeec

Firmansyah, D. (2013). The Influence of Family Backgrounds Toward Student's Saving Behavior: A Survey of College Students in Jabodetabek. SSRN Electronic Journal, 4(1), 1-6. https://doi.org/10.2139/ssrn.2358346

Ghufron, M. N., \& Risnawitaq, R. S. (2017). Teori-teori psikologi (2nd ed.). Ar-Ruzz Media.

Kamawar, D., Connolly, K., Astle-Rahim, A., Smygwaty, S., \& Vendetti, C. (2019). Preschoolers' Saving Behavior: The Role of Planning and Self-Control. Child Development, 90(4), e407-e420. https://doi.org/10.1111/cdev.13037

Lee, Y. J., Kim, K. S., \& Lee, H. J. (2017). Demo abstract: Smart piggy bank: In-home banking system for children. Proceedings - 2017 IEEE/ACM 2nd International Conference on Internet-of-Things Design and Implementation, IoTDI 2017 (Part of CPS Week), 293-294. https://doi.org/10.1145/3054977.3057318

León Peque, M. S., \& Casas, C. (2018). Coink - An IoT Piggy Bank. Retrieved from Hackster.io website: https://www.hackster.io/cojoteam/coink-an-iot-piggy-bank-6e3f83

Lewis, A., \& Scott, A. J. (2000). The Economic Awareness, Knowledge and Pocket Money Practices of a Sample of UK Adolescents: A Study of Economic Socialisation and Economic Psychology. Citizenship, Social and Economics Education, 4(1), 34-46. https://doi.org/10.2304/csee.2000.4.1.34

PENNIE: An Arduino Powered IoT Piggy Bank. (2020). Retrieved from SVA MFA Products of Design website: https://productsofdesign.sva.edu/blog/pennie

Royce, W. W. (1970). Managing the Development of Large Software Systems (1970). Proceedings of IEEE WESCON, (8), 328-338. https://doi.org/10.7551/mitpress/12274.003.0035

Sirine, H., \& Utami, D. S. (2016). Faktor-Faktor Yang Memengaruhi Perilaku Menabung Di Kalangan Mahasiswa. Jurnal Ekonomi Dan Bisnis, 18(1), 27. https://doi.org/10.24914/jeb.v19i1.479

Teaching Kids the Value of Money. (n.d.). Retrieved October 14, 2019, from Cambridge Credit Counseling Corp website: https://www.cambridge-credit.org/teaching-kids-the-value-of-money.html 